\title{
ERUPCIONES < 3800 a.P. DEL VOLCÁN RINCÓN DE LA VIEJA, COSTA RICA
}

\author{
Gerardo J. Soto $^{1 *}$, Guillermo E. Alvarado ${ }^{1} \&$ Sonja Goold $^{2}$ \\ 1 Área de Auscultación Sísmica y Volcánica, Instituto Costarricense de Electricidad, \\ Apdo 10032-1000, San José, Costa Rica \\ 2 Department of Earth Sciences, Dalhousie University, \\ Halifax, Nova Scotia, Canadá B3H 4R2 \\ * Dirección actual: Apdo. 360-2350 San Francisco Dos Ríos, Costa Rica \\ katomirodriguez@yahoo.com
}

(Recibido 19/4/04; aceptado: 16/8/04)

\begin{abstract}
Rincón de la Vieja is the only active volcano in the Guanacaste Range. Its activity has been characterized by frequent gas and steam emissions, and periodical phreatic and phreatomagmatic eruptions (isolated or clustered in 5-7 year intervals, every $40 \pm 10$ years), normally accompanied by hot lahars, concentrated mainly on its Caribbean watershed. Prehistoric pyroclastic flows (1520 B.P.) have been mapped and described, as far as $10 \mathrm{~km}$ from the active crater. A sub-plinian layer (3770 B.P.) is preserved on the WSW flank, in accordance with the prevailing trade winds. Both deposits have pumice and scoria. The pumices are geochemically and petrographically similar, but scoriae are different. Scoriae from the pyroclastic flows are more similar to those erupted recently. This suggests that remnant dacitic magma from the subplinian eruption, was erupted due to the intrusion of andesitic magma, which once erupted, formed scoria-pyroclastic flows. This latter magma has remained in a shallow reservoir and would have fed the eruptions of the last 1500 years.
\end{abstract}

Keywords: Rincón de la Vieja volcano, historical eruptions, prehistoric eruptions, subplinian eruption, scoria flows, phreatomagmatic eruptions, lahars.

RESUMEN: El volcán Rincón de la Vieja es el único volcán activo en la Cordillera de Guanacaste. Históricamente, su actividad se ha caracterizado por frecuentes emisiones de gases y vapores, y erupciones freáticas y freatomagmáticas periódicas (aisladas o agrupadas en un lapso de 5-7 años, cada $40 \pm 10$ años), acompañadas normalmente por lahares calientes. Flujos piroclásticos prehistóricos (1520 a.P.) se han mapeado y caracterizado hasta por lo menos $10 \mathrm{~km}$ de distancia del cráter activo. Una capa subpliniana (3770 a.P.) se preserva en el flanco WSW, acorde con la dirección del viento predominante. Ambos depósitos (flujos piroclásticos y caída subpliniana) contienen pómez y escorias. Las pómez son geoquímica y petrográficamente similares, mas las escorias son diferentes. Las escorias de los flujos piroclásticos muestran similitud con los magmas eruptados recientemente. Esto sugiere que un magma dacítico remanente de la erupción subpliniana fue eruptado por efecto de la intrusión de magma andesítico, que al ser a su vez eruptado, formó flujos piroclásticos escoriáceos. Este mismo magma ha permanecido en una cámara somera y habría alimentado las erupciones de los últimos 1500 años.

Palabras clave: Volcán Rincón de la Vieja, erupciones históricas, erupciones prehistóricas, erupción subpliniana, flujos de escoria, erupciones freatomagmáticas, lahares. 


\section{INTRODUCCIÓN}

El macizo volcánico Rincón de la Vieja se localiza $25 \mathrm{~km}$ al NNE de la ciudad de Liberia (Fig. 1). La altura máxima del complejo es de 1916 m s.n.m, cubre una extensión de más de $400 \mathrm{~km}^{2}$ y tiene un volumen de $200 \mathrm{~km}^{3}$. Exhibe una forma elíptica de $20 \mathrm{~km}$ de largo, con el eje mayor en sentido WNW-ESE. La parte cuspidal se presenta relativamente llana, con un ancho de 1-1,5 km. Contrariamente a los otros macizos volcánicos de Costa Rica, los 9 focos eruptivos del Rincón de la Vieja se alinean casi paralelos al eje de la cordillera volcánica (Fig. 2a). Además de los cráteres que se desarrollaron en la arista cuspidal, no se conocen conos parásitos en los

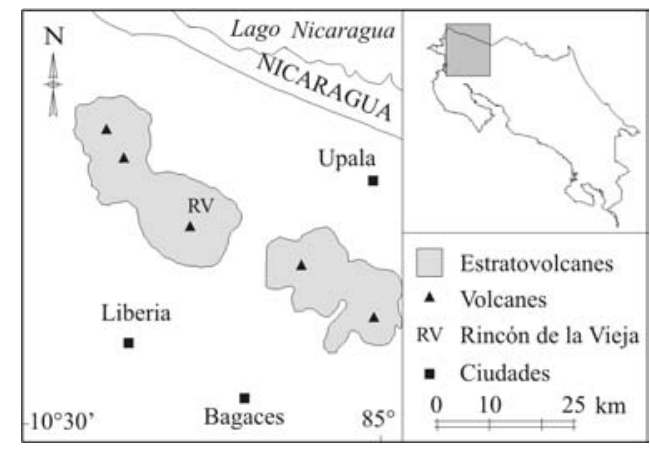

Fig. 1: Ubicación del volcán Rincón de la Vieja. flancos. El cráter Activo (Fig. 2b) aloja desde hace centurias una laguna termomineral, con colores, volumen y temperatura variables, pero de marcada acidez.

Los productos volcánicos más recientes, de un vulcanismo casi exclusivamente explosivo ( $\leq 27000$ años; Kempter et al., 1996), provienen de las cuatro estructuras volcánicas más occidentales (Fig. 2a). La última lava, al suroeste del cráter activo, parece ser un poco más vieja que 4000 años. Los productos eruptivos son de composición andesítica con escasas andesitas basálticas y dacitas. Los productos históricos son de carácter andesítico y las más ricas en sílice $\left(\mathrm{SiO}_{2}=56\right.$ $60 \%$ ) en toda la Cordillera de Guanacaste (Carr et al., 1986; Chiesa et al., 1994; Kempter et al., 1996; Boudon et al., 1996).

Con base en trabajos cartográficos para la evaluación del peligro volcánico del Rincón de la Vieja (Soto et al., 2003), se determinó que en los últimos 4000 años el volcán ha tenido una erupción subpliniana $3770 \pm 130$ años antes del presente (a.P., Cuadro 1), una erupción con flujos piroclásticos de escorias y una serie de erupciones menores, cuyo conjunto son el tema de este trabajo. Se enfoca en la estratigrafía y evolución de la única erupción subpliniana reconocible ("Depósito de Tefra de Río Blanco" sensu Kempter, 1997), el mapeo de la distribución de los flujos piroclásticos en el flanco meridional, su estratigrafía y

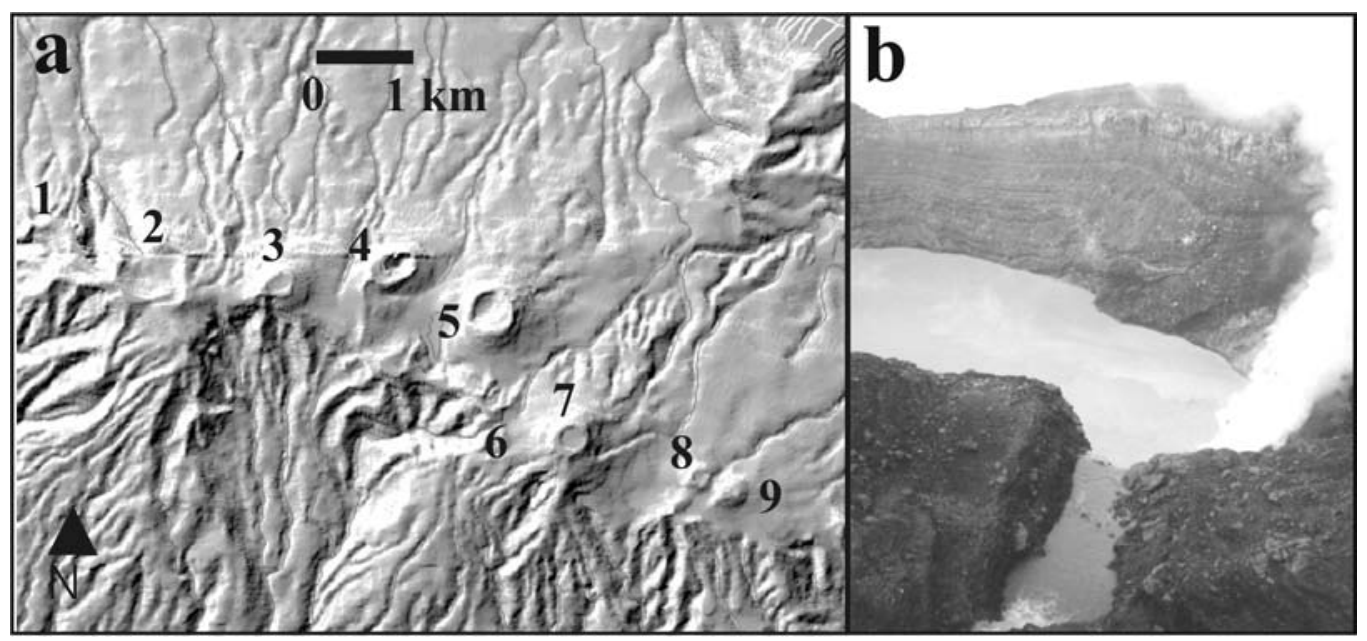

Fig. 2: a) Modelo de elevación digital de la cima del Rincón de la Vieja, con las 9 estructuras volcánicas numeradas. El 3 es el cono Von Seebach, el 4 es el cráter Activo y el 5 el Rincón de la Vieja de los mapas. b) El cráter Activo con la laguna caliente en 1995. 
edad, y la estratigrafía de los depósitos más recientes (erupcionados desde el cráter Activo), cuya modalidad eruptiva parece ser muy similar a la de los eventos eruptivos de las últimas tres décadas y media del siglo XX (cf. Boudon et al., 1996, 1997a). Las erupciones históricas, originadas todas en el cráter Activo, son tratadas en detalle, en particular los depósitos de las erupciones de la década de 1990.

\section{ERUPCIONES PREHISTÓRICAS}

\section{Tefra de caída Río Blanco}

Kempter (1997) nominó "Depósito de Tefra Río Blanco” al depósito de caída de pómez más reciente del Rincón de la Vieja, que se distribuye a lo largo de un eje WSW desde el cráter activo, hasta unos $30 \mathrm{~km}$ de distancia. Corresponde con el depósito de una erupción subpliniana, cuya edad había sido determinada en $3490 \pm 105$ años a.P. (Melson, 1988) y cuya calibración da $3770 \pm 130$ a.P. (Cuadro 1). Una serie de tiestos cerámicos encontrados en el suelo que sobreyace al depósito, pertenece a la Fase Catalina, de edad 300 a.C. a 300 d.C., equivalente a 1650-2250 a.P. (M. Sánchez, com. escrita, en Soto et al., 2003) e indica una congruencia cronológica.

La mayor parte del depósito es una pómez beige, con cantidades variables de escorias negras, piroclastos bandeados (pómez y escoria) y muy pocos líticos. Para evaluar los mecanismos de erupción se estudiaron 6 cortes claves en partes planas de la falda occidental del volcán (Cuadro 2, Fig. 3), de donde podemos deducir que la erupción se dio en varias fases y cuya secuencia más completa se ve en el corte Borinquen Adentro (Fig. 4).

Kempter (1997) había observado al menos veinte diferentes capas en las partes proximales al cráter Activo. En Borinquen Adentro son distinguibles 22 capitas, que se agrupan en

Cuadro 1

Edades de radiocarbono usadas en este trabajo

\begin{tabular}{cccc}
\hline Muestra & Edad sin calibrar (a.P.) & Referencia & Edad calibrada (a.P)* $^{*}$ \\
\hline Tefra Unidad Grupo 2 & $270000 \pm 560$ & Kempter et al., 1996 & - \\
Tefra Río Blanco & $3490 \pm 105$ & Melson, 1988 & $3770 \pm 130$ \\
Flujos sector norte & $1600 \pm 60$ & Soto et al., 2003 & $1520+80-110$ \\
\hline
\end{tabular}

*Con base en Stuiver et al. (1998)

Cuadro 2

Ubicación de las secciones tefroestratigráficas para el estudio de la Tefra Río Blanco y los flujos piroclásticos del lado norte (Fig. 3).

\begin{tabular}{lccc}
\hline Sitio & Coordenadas & $\begin{array}{c}\text { Distancia al } \\
\text { volcán (km) }\end{array}$ & Facies \\
\hline a- Quebrada Zanjonuda & $317,46 \mathrm{~N}-392,40 \mathrm{E}$ & 5,4 & Proximal media (flujos) \\
b- Pénjamo abajo & $320,96 \mathrm{~N}-393,50 \mathrm{E}$ & 9,1 & Distal (flujos) \\
c- Borinquen Adentro & $309,80 \mathrm{~N}-381,82 \mathrm{E}$ & 8,7 & Proximal media \\
d- Borinquen Afuera & $309,22 \mathrm{~N}-381,90 \mathrm{E}$ & 8,8 & Proximal externa \\
e- Loma Camastro-Q. Grande & $310,01 \mathrm{~N}-373,29 \mathrm{E}$ & 16,7 & Distal media \\
f- Loma Camastro & $308,92 \mathrm{~N}-373,37 \mathrm{E}$ & 17,1 & Distal media \\
g- Q. Grande-Lilas & $312,53 \mathrm{~N}-377,93 \mathrm{E}$ & 12,2 & Distal media \\
h- C. Fortuna NW & $309,81 \mathrm{~N}-377,14 \mathrm{E}$ & 13,2 & Distal media \\
\hline
\end{tabular}




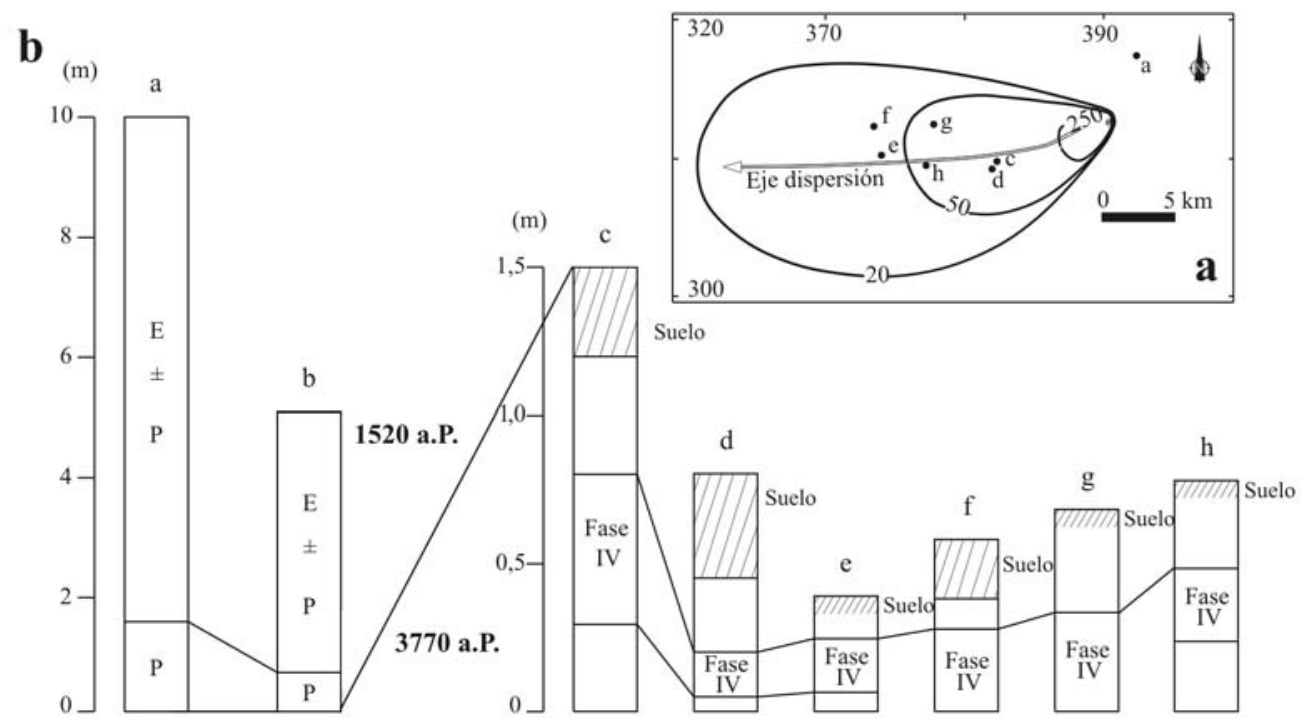

Flujo de escoria (E) y pómez (P)

Tefra Rio Blanco

Fig. 3: a) Curvas isopacas (en cm) del depósito de la erupción subpliniana Río Blanco (modificada de Kempter, 1997), y los sitios estudiados mostrados en las columnas de 3b. b) Correlación entre las columnas estudiadas de la Tefra Río Blanco y los flujos piroclásticos.

seis series o fases. La secuencia sobreyace a un suelo negro; de la base al techo, es la siguiente (Fig. 4):

(I) Sobreyace a un suelo negro; la base es una ceniza a lapilli marrón, rica en cristales sueltos (plagioclasas y piroxenos), e incluye pómez y escorias, con gradación normal. Documenta el evento de apertura de la erupción.

(II) Un conjunto de cinco capas de lapilli separadas por capitas de ceniza documenta una fase pulsante. El tamaño de grano y el contenido de escorias aumentan hacia el techo (Cuadro 3) y la cantidad de piroclastos bandeados es significativa en la parte superior.

(III) Una capa que contiene bastantes escorias y líticos sobre y subyacida por cenizas, que abren y cierran la fase. La cantidad y tamaño de las escorias son las mayores en toda la secuencia, aunque el espesor de la capa no es muy grande (Cuadro 3).

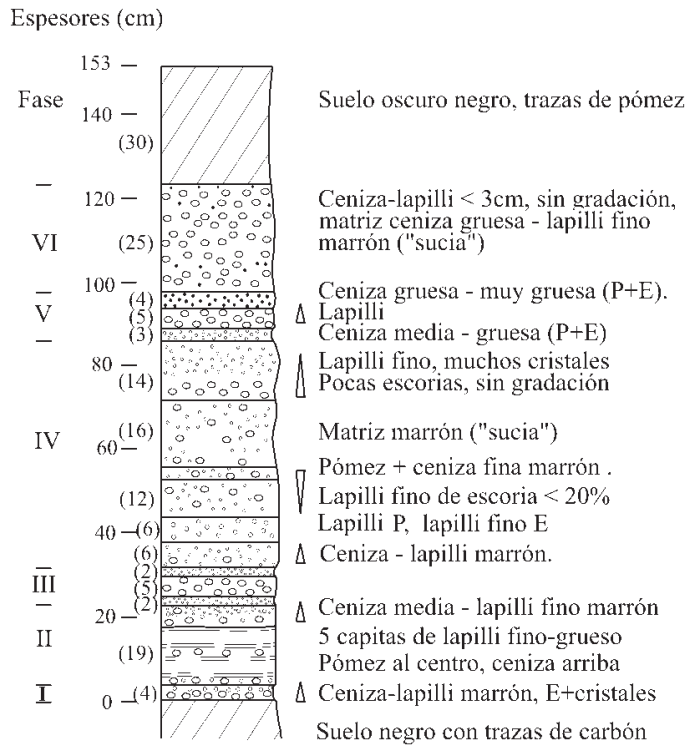

$\Delta$ Gradación normal $\nabla$ Gradación inversa P: Pómez E: Escoria

Fig. 4: Columna estratigráfica del depósito de caída de la Tefra Río Blanco en el sitio Borinquen Adentro, donde se muestran las diferentes fases de la erupción. 
(IV) La parte principal del depósito, que se puede dividir en cinco subfases. La parte inferior son tres pulsos, que se abre con gradación positiva y cierra con gradación inversa. Tiene también un contenido alto de escorias y clastos mezclados, que disminuyen en las dos subfases superiores (Cuadro 3). La fase intermedia contiene mucha matriz fina. La fase superior tiene gradación normal y es pobre en matriz fina.

(V) Esta fase abre y cierra con una ceniza media a gruesa, con una capa de caída con gradación normal en el medio.

(VI) La última fase es un solo evento, también con bastante matriz fina, casi exclusivamente con pómez y sin líticos.
El contenido de líticos es muy bajo a lo largo de toda la erupción y hacia el techo es cada vez más pobre (Cuadro 3).

La granulometría del depósito (Cuadro 4) nos indica que la fase III es de una granulometría gruesa, con poca matriz y buena granoselección, propia de caída y de una explosión magmática. La fase IV intermedia tiene una granulometría gruesa, comparable a la anterior, aunque el contenido de cenizas medias hasta polvo volcánico es significativo, con una granoselección mediana, lo que confirma una componente freatomagmática importante, quizás la fase más violenta de la erupción. En la fase de cierre (la VI), el contenido de granulometrías menores que cenizas medias y una granoselec-

Cuadro 3

Contenido de pómez, escoria y líticos y tamaño máximo (en mm) en diferentes horizontes de la Tefra Río Blanco en el sitio Borinquen Adentro (Fig. 4), para la fracción > 2mm

\begin{tabular}{cccccccc}
\hline & Nivel & \multicolumn{2}{c}{ Pómez } & \multicolumn{2}{c}{ Escoria } & \multicolumn{2}{c}{ Líticos } \\
& & $\%$ & máx & $\%$ & máx & $\%$ & máx \\
\hline & VI* & 96,4 & 29 & 3,4 & 13 & 0,2 & 5 \\
$\mathrm{~T}$ & IV superior & 96,6 & 28 & 3,3 & 8 & 0,1 & 4 \\
$\mathrm{E}$ & IV intermedio & 97,2 & 38 & 2,3 & 13 & 0,5 & 9 \\
$\mathrm{C}$ & IV inferior & 89,2 & 23 & 9,9 & 16 & 0,9 & 6 \\
$\mathrm{H}$ & III & 83,6 & 35 & 14,5 & 25 & 1,9 & 9 \\
$\mathrm{O}$ & II superior+ & 89,9 & 21 & 9,3 & 13 & 0,8 & 6 \\
& II inferior & 96,5 & 15 & 2,3 & 8 & 1,2 & 6 \\
\hline
\end{tabular}

*: gran cantidad de finos adheridos hacen difícil discernir entre pómez y escoria

+: muchas escorias y pómez mezcladas hacen difícil la separación entre una y otra

Nota: El tamaño máximo se refiere al promedio de los 5 clastos más grandes.

Cuadro 4

Granulometría de los diferentes niveles de la Tefra Río Blanco (porcentaje pasando) en el sitio Borinquen Adentro (Fig. 4)

\begin{tabular}{cccccccccc}
\hline mm & - & Grano & II inf & II sup & III & IV inf & IV med & IV sup & VI \\
\hline 64 & -6 & lap mg & - & - & 100 & - & 100 & - & - \\
32 & -5 & lap g & - & 100 & 98 & 100 & 99 & 100 & 100 \\
16 & -4 & lap m & - & 99 & 85 & 98 & 83 & 95 & 96 \\
8 & -3 & lap f & 99 & 91 & 61 & 85 & 62 & 77 & 84 \\
4 & -2 & lap mf & 88 & 67 & 43 & 68 & 50 & 59 & 70 \\
2 & -1 & cen mg & 67 & 42 & 29 & 36 & 42 & 41 & 55 \\
1 & 0 & cen g & 40 & 24 & 16 & 17 & 34 & 20 & 39 \\
0,5 & 1 & cen m & 15 & 15 & 6 & 6 & 29 & 5 & 23 \\
0,25 & 2 & cen f & 9 & 9 & 5 & 5 & 27 & 3 & 15 \\
0,125 & 3 & cen mf & 8 & 7 & 4 & 4 & 25 & 2 & 9 \\
0,063 & 4 & polvo & 6 & 4 & 3 & 3 & 20 & 1 & 7 \\
\hline
\end{tabular}

lap: lapilli; cen: ceniza; mg: muy grueso; g: grueso; m: medio; f: fino; mf: muy fino; sup: superior; med: medio; inf: inferior. 
ción de mediana a buena, corrobora también una contribución freatomagmática importante. Kempter (1997) interpretó que la erupción ocurrió en dos fases. Había notado que las granulometrías más grandes se encuentran en el medio y parte superior del depósito y que bajo la capa intermedia había una pequeña interrupción de la erupción. Él observó una inflexión de los diámetros de clastos, cerca de $4 \pm 0,8 \mathrm{~km}$ de la fuente, en donde las facies proximales están engrosadas. Además, observaba abundantes pómez balísticas y líticos en la parte inferior de la secuencia, lo que le hizo suponer una variabilidad en la explosividad y altura de la columna eruptiva, en donde la primera fase fuera menos explosiva y causara un espesor anómalo del depósito en las facies proximales.

\section{Mecanismo de erupción de la Tefra Río Blanco}

Las pómez de Río Blanco documentan el único evento explosivo de grandes dimensiones en la historia reciente del volcán (al menos 0,5 Ma). Una inyección de magma andesítico disparó la erupción, cuya primera fase fue de apertura del cráter. La segunda fase es pulsante, con un aumento de la energía hacia el final. La tercera fase abre y cierra con eventos freatomagmáticos (cenizas finas), con una sola gran explosión en el medio, en donde la contribución de magma andesítico se ha ido incrementando y en donde la mezcla de ambos magmas es más eficaz. La cantidad de líticos documenta una fase de apertura del conducto. Estas primeras tres fases corresponden con lo que Kempter (1997) atribuyó como la primera etapa de la erupción.

La cuarta fase es la de mayor espesor y tamaño de grano, y es la fase de clímax de la erupción, con pulsos que permiten la incorporación de agua subterránea y la generación de explosiones freatomagmáticas en el medio. La incorporación de magma andesítico y de líticos decrece hacia el tope y sugieren un conducto abierto con poca incorporación de materiales de sus paredes. La quinta fase es una explosión de menor cuantía, con eventos freatomagmáticos al inicio y final. La última fase es una explosión importante, en donde la componente freatomagmática es trascendente, quizás por el decrecimiento de la presión del magma e invasión de agua subterránea. La cantidad de escorias andesíticas y líticos y sus tamaños son comparables a la fase cuarta terminal.

Kempter (1997) calculó un volumen de $0,25 \mathrm{~km}^{3}$ de material eruptado (equivalente de roca densa de $0,1 \mathrm{~km}^{3}$ ), del cual $\sim 10 \%$ es magma andesítico. Con base en las isopletas de líticos calculó la altura de la columna eruptiva en $16 \mathrm{~km}$ (subpliniana). Según nuestras observaciones, puesto que los líticos más grandes están distribuidos durante la fase de clímax (la IV), este cálculo debe ser tomado como la altura de la columna durante esta fase. Ese mismo autor, al asumir dos fases casi continuas de la erupción, calculó una tasa de emisión de material de $1,0 \times 10^{7} \mathrm{~kg} \mathrm{~s}^{-1}$ y una duración mínima de la erupción de 9 horas. Como la erupción no se dio en dos, sino en seis fases, pulsantes y discontinuas, la tasa de emisión total debe haber sido menor, aunque durante la fase de clímax podría ser de ese orden, y la duración de la erupción ha de haber sido de uno a dos días (cf. la tabla 6.4 de Cas \& Wright, 1988).

\section{Los flujos piroclásticos del lado norte}

Kempter (1997; p. 135) había escrito que "un flujo piroclástico asociado con la Tefra Río Blanco se extiende al noreste del cráter Activo por varios kilómetros". También fueron mencionados por Paniagua et al. (1996). En el sector norte del volcán, estos flujos se encuentran restringidos a los valles de los ríos Azul y Pénjamo (Fig. 5), desde la cota de 800 m s.n.m. y se distribuyen aguas abajo hasta la confluencia con el río Cucaracho, unos $10 \mathrm{~km}$ al norte del cráter Activo, pero son el producto de una erupción diferente. Son flujos de pómez en la base y escorias en el techo, con mezcla mecánica de ambos durante la erupción. Desde el cráter Activo hasta $5 \mathrm{~km}$ al norte, los flujos de escorias se presentan medianamente soldados y en el resto del trecho no muestran soldamiento, aunque la matriz es dura. 


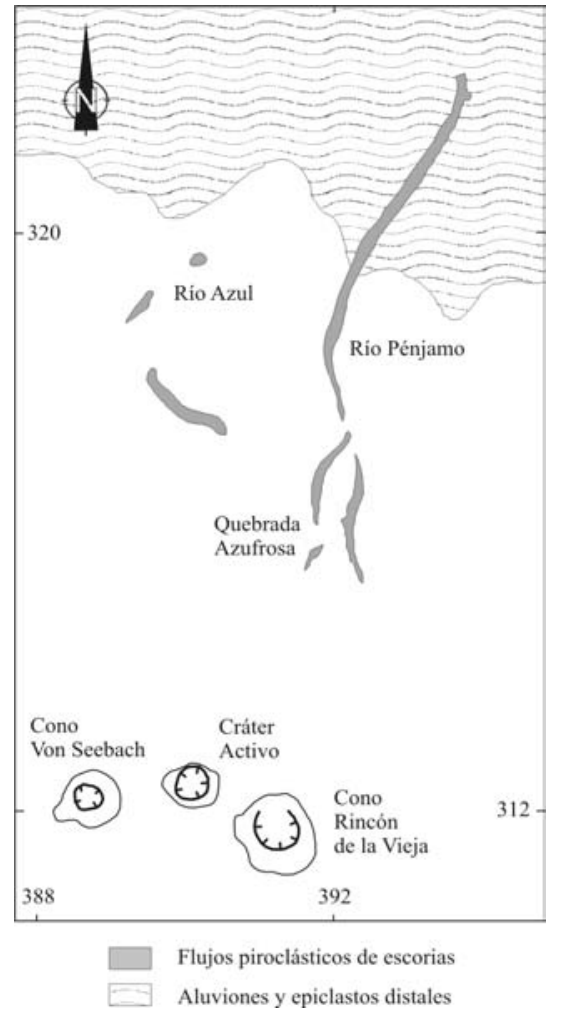

Fig. 5: Mapa de distribución de los flujos de escoria.
La figura 6a muestra la columna estratigráfica en la intersección de la quebrada Zanjonuda con el río Pénjamo, donde aflora en una catarata el flujo de escorias (Fig. 6b). Los subyace un depósito aluvial con matriz arcillificada gris rojizo, en superficie. La base del depósito es un flujo canalizado con un espesor de hasta $1,5 \mathrm{~m}$, rico en pómez (20 a $30 \mathrm{~cm}$ de diámetro) y escorias en menor cantidad, con estratificación y gradación normal crudas, sostén por matriz ( 40\%). Contiene troncos carbonizados, uno de los cuales fue datado con ${ }^{14} \mathrm{C}$ y dio una edad calibrada de 1520 (+80-110 años a.P.) (Cuadro 1). Es sobreyacida por un nivel centimétrico de cenizas gruesas, discontinuo y con laminación inclinada (surges?). Lo sobreyace en contacto neto y aparentemente erosivo el flujo de escorias soldadas, algunas densas y lustrosas sin vesicularidad $(\Phi<42 \mathrm{~cm})$, líticos andesíticos $(<10 \%, \Phi<27 \mathrm{~cm})$, pómez $(<5 \%$, $\Phi<7 \mathrm{~cm}$ ) y escorias mezcladas (franjas claras y oscuras, $<5 \%, \Phi<12 \mathrm{~cm})$. El flujo es masivo y muestra diaclasas de enfriamiento en forma de columnas en sus partes central e inferior (Fig. 6).

Las fases no soldadas afloran a lo largo del cauce de los ríos Pénjamo y Azul y están claramente encañonadas, con contactos en forma de

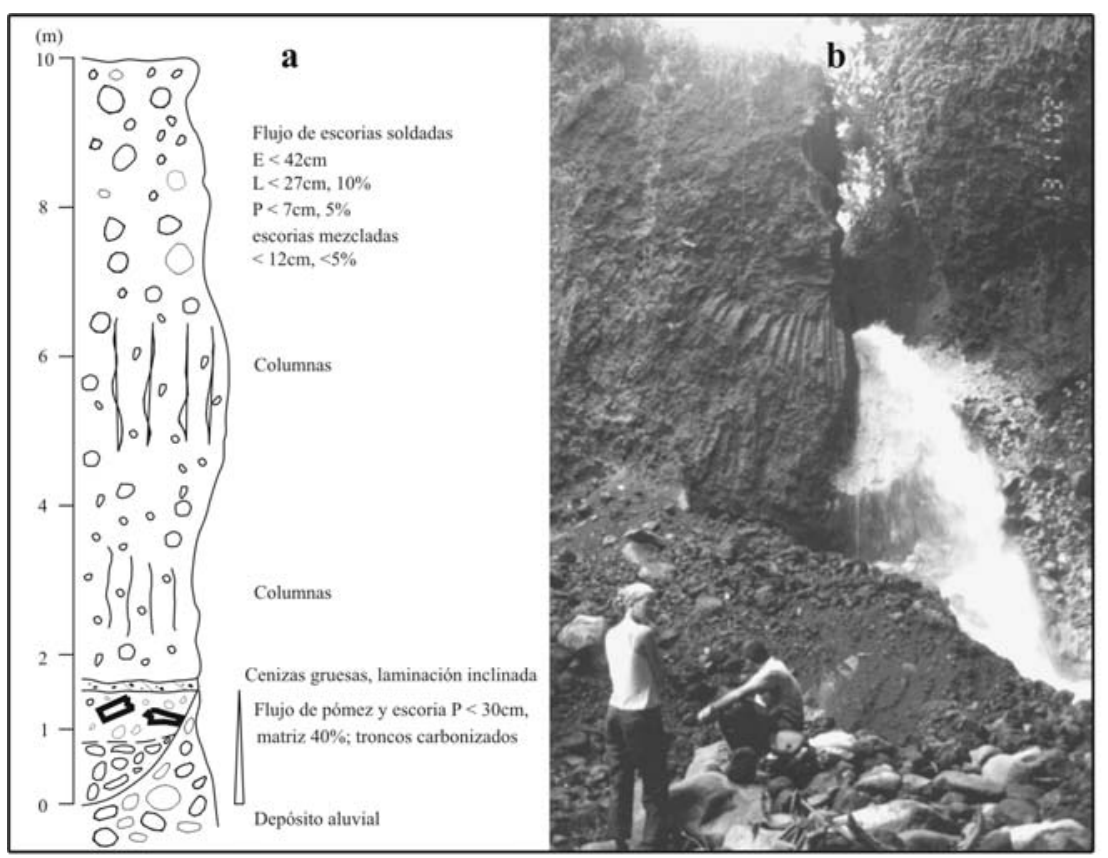

Fig. 6: a) Columna del flujo de escorias en quebrada Zanjonuda. b) El afloramiento en la catarata de la quebrada Zanjonuda, que muestra las columnas de enfriamiento. 
cuña, con espesores máximos de unos 4 a $5 \mathrm{~m}$ hasta encontrarse con el cañón del río Cucaracho. El afloramiento Pénjamo Abajo (Fig. 3b, Cuadro 2) muestra la base subyacente formada por lahares grises con clastos redondeados decimétricos, soportados por una matriz arcillosa, cuya parte superior grada a un suelo café oscuro a negro de $\sim 20 \mathrm{~cm}$ de espesor. La base del depósito piroclástico es una ceniza gris muy fina a media, laminada, de $3 \mathrm{~cm}$ de espesor máximo, que disturba erosivamente al suelo, y que contiene abundante material carbonizado de tamaño milimétrico (posible ground surge). La sobreyacen $17 \mathrm{~cm}$ de pómez pobremente seleccionadas $(\Phi$ $<8 \mathrm{~cm}$ ) con una matriz de ceniza gruesa, con gradación inversa, con granos aislados de escorias oscuras. El contacto inferior es difuso y el contacto superior es neto y erosivo, que la hace adelgazarse. La siguiente capa es una pómez con soporte por granos $(\Phi<2 \mathrm{~cm})$, poca matriz de ceniza muy gruesa a lapilli fino de unos $6 \mathrm{~mm}$, con escorias $(<5 \%, \Phi<1 \mathrm{~cm})$, algunos troncos decimétricos y ramas carbonizadas, gradación normal y un espesor variable entre 30 y $62 \mathrm{~cm}$. Corona la secuencia un flujo de escorias masivo de 4,5 $\mathrm{m}$ de espesor, soportado por una matriz dura, con una leve gradación normal en la base e inversa en el techo. Las escorias en la base son $\leq 17 \mathrm{~cm}$ de diámetro y se hacen más abundantes en el techo, las pómez escasas, algunas mezcladas con bandeamiento, los líticos $<10 \%$, algunos rojizos de hasta $2 \mathrm{~cm}$. Flujos similares afloran en la margen derecha del río Azul (verbigracia en un tajo en 319,39N390,45E).

\section{Comparación de la Tefra Río Blanco y los flujos de escorias: evolución eruptiva}

Una comparación entre los flujos piroclásticos del lado norte y la secuencia de pómez de caída de Río Blanco, puede hacerse con base en los siguientes criterios: 1) La edad de radiocarbono obtenida en la base de ambos depósitos; 2) la composición petrográfica y química de los clastos pumíticos y de escorias; 3) la distribución de escorias y pómez a lo largo de la secuencia eruptiva.
Los datos de ${ }^{14} \mathrm{C}$ son concluyentes: son dos eventos diferentes (Cuadro 1). La petrografía que se detalla en el Cuadro 5 muestra gran similitud entre las pómez de ambos depósitos (de caída y flujo). La composición química de los elementos mayores y trazas (Cuadro 6) nos muestra asimismo, grandes similitudes entre las pómez de caída y de flujo, mientras que las escorias no se parecen; más bien, las escorias de flujo son similares a los productos más recientes, p. ej. una bomba eruptada en 1995. Muchos valores de la escoria de caída analizada por Kempter (1997) son intermedios entre la de caída y la de flujo.

Los flujos piroclásticos del norte muestran al menos cuatro fases de flujo, donde las primeras tienen abundantes pómez y ground surges asociados, con una cantidad de escorias apreciable. La fase de flujo principal muestra abundantes escorias en toda la secuencia y pocas pómez, aunque son frecuentes los fragmentos bandeados. Como se vio, en la Tefra de caída Río Blanco, las escorias tienen una distribución variable en el trayecto de la columna estratigráfica.

Con base en los elementos disponibles, podemos hipotetizar una evolución de los escenarios eruptivos (Fig. 7):

1. El magma ácido de la Tefra Río Blanco era el remanente diferenciado en una cámara magmática, pasiva por un largo período. Al haber ocurrido una nueva inyección de magma andesítico, documentado por las escorias, se disparó la erupción Río Blanco (cf. Cas \& Wright, 1988: capítulo 3.3). El mecanismo de erupción estuvo controlado por la invasión de magma andesítico en una cámara diferenciada, que disparó térmicamente la erupción. Conforme avanzó la mezcla mecánica (aspecto bandeado de las pómez y escorias), se iniciaron las fases segunda y tercera de la erupción, en donde la contribución de magma andesítico fue más voluminosa (subfases intermedia y terminal de la tercera fase), con una fase subpliniana importante (cuarta fase), y luego decayeron la violencia de la erupción y el contenido de magma andesítico. Al terminar la 
Cuadro 5

Síntesis petrográfica de rocas de los flujos piroclásticos del norte y la Tefra Río Blanco

\begin{tabular}{|c|c|c|c|}
\hline Procedencia & Matriz & Fenocristales & Comentarios \\
\hline $\begin{array}{l}\text { Pómez base flujo } \\
\text { de escoria } \\
\text { (Pénjamo Abajo) }\end{array}$ & $\begin{array}{l}\text { Vítrea de color claro } \pm \\
\text { microlitos Pl acicular } \pm \mathrm{Px} ?\end{array}$ & $\begin{array}{l}\text { Pl } 10 \%+\text { Mt } 10 \% \\
+\mathrm{O} 11 \% \pm \operatorname{Px} 1 \%\end{array}$ & $\begin{array}{l}\text { Profusamente } \\
\text { vesicular }\end{array}$ \\
\hline $\begin{array}{l}\text { Pómez bandeada } \\
\text { (Pénjamo Abajo) }\end{array}$ & $\begin{array}{l}\text { Vítrea de color claro } \pm \\
\text { microlitos Pl acicular } \pm \text { Px? }\end{array}$ & $\begin{array}{l}\text { Pl } 10 \%+\text { Mt } 10 \% \\
+ \text { Ol } 1 \% \pm \text { Px } 0,5 \%\end{array}$ & $\begin{array}{l}\text { Muy vesicular. } \\
\text { Bandas de vidrio } \\
\text { oscuro y microlitos }\end{array}$ \\
\hline $\begin{array}{l}\text { Escoria } \\
\text { (Pénjamo Abajo) }\end{array}$ & $\begin{array}{l}\text { Vítrea oscura a } \\
\text { microlítica } \pm \mathrm{Pl} \text { acicular } \pm \mathrm{Px} ?\end{array}$ & $\begin{array}{l}\text { P1 } 5 \%+\text { Mt } 5 \% \\
+ \text { Px } 1 \%\end{array}$ & Vesicular \\
\hline $\begin{array}{l}\text { Flujo de escoria } \\
\text { (Zanjonuda) }\end{array}$ & $\begin{array}{l}\text { Microlítica a vítrea, } \\
\text { microlitos aciculados }\end{array}$ & $\begin{array}{l}\text { Pl } 20 \%+\text { Px } 5 \%+. \\
\text { Mt } 5 \% \pm \text { Ol } 1 \% . \\
\text { Fracturados }\end{array}$ & $\begin{array}{l}\text { Alterna matriz oscura } \\
\text { y clara }\end{array}$ \\
\hline $\begin{array}{l}\text { Clastos densos } \\
\text { flujos de escoria } \\
\text { (Zanjonuda) }\end{array}$ & $\begin{array}{l}\text { Microlítica a vítrea, } \\
\text { microlitos aciculados }\end{array}$ & $\begin{array}{l}\text { Pl } 10+\text { Mt } 5 \%+ \\
\text { Ol? } \pm \text { Px? }\end{array}$ & $\begin{array}{l}\text { Alterna matriz } \\
\text { oscura y clara, orientación } \\
\text { de flujo en bandas claras }\end{array}$ \\
\hline $\begin{array}{l}\text { Pómez Fase III } \\
\text { (Borinquen Adentro) }\end{array}$ & $\begin{array}{l}\text { Vítrea de color claro } \pm \\
\text { microlitos Pl acicular } \pm \text { Px }\end{array}$ & $\begin{array}{l}\text { Pl } 15 \%+\text { Mt } 10 \% \\
+ \text { Ol } 1 \% \pm \text { Px } 1 \%\end{array}$ & Muy vesicular \\
\hline
\end{tabular}

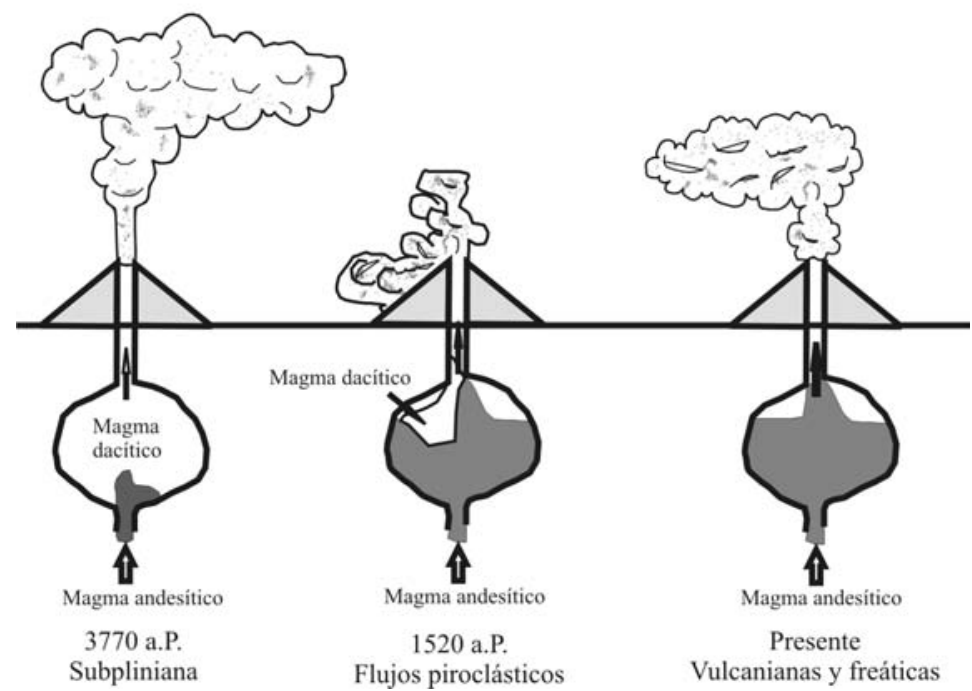

Fig. 7: Evolución de los escenarios eruptivos y los magmas involucrados en el Rincón de la Vieja.

erupción, parte del magma dacítico permaneció en la cámara.

2. El residuo de magma dacítico fue incorporado en las fases tempranas de la erupción de hace 1520 años, cuando un magma andesítico ascendió y originó los flujos piro- clásticos del lado norte. Ese tipo de magma ha permanecido hasta el presente. Las similitudes químicas de las pómez y la diferencia química entre las escorias contenidas en Río Blanco y en los flujos, que más bien se parecen a las escorias 
Cuadro 6

Composición química de las rocas de los flujos piroclásticos del norte, la Tefra Río Blanco y de la erupción de 1995

\begin{tabular}{|c|c|c|c|c|c|c|c|}
\hline Muestra & $\mathrm{RBT}^{*}$ & $\begin{array}{c}031202 \\
\text { RV03PU }\end{array}$ & $\begin{array}{c}121102 \\
02 \mathrm{RV}\end{array}$ & RBMT* & $\begin{array}{c}031202 \\
\text { RV03ES }\end{array}$ & $\begin{array}{c}121102 \\
04 R V\end{array}$ & RV1195 \\
\hline Tipo & Pómez caída & Pómez caída & Pómez flujo & Escoria caída & Escoria caída & Escoria flujo & Bomba 1995 \\
\hline $\mathrm{SiO}_{2}$ & 66,40 & 65,39 & 65,45 & 57,60 & 55,30 & 60,15 & 60,62 \\
\hline $\mathrm{MnO}$ & 0,10 & 0,10 & 0,10 & 0,17 & 0,14 & 0,12 & 0,15 \\
\hline $\mathrm{Fe}_{2} \mathrm{O}_{3}$ & 3,88 & 5,24 & 5,42 & 8,70 & 8,65 & 7,11 & 7,04 \\
\hline $\mathrm{MgO}$ & 1,00 & 2,02 & 2,02 & 3,20 & 4,27 & 3,07 & 3,53 \\
\hline $\mathrm{TiO}_{2}$ & 0,47 & 0,57 & 0,61 & 0,79 & 0,74 & 0,66 & 0,70 \\
\hline $\mathrm{CaO}^{2}$ & 3,70 & 4,34 & 4,90 & 6,92 & 8,13 & 6,54 & 7,12 \\
\hline $\mathrm{Al}_{2} \mathrm{O}_{3}$ & 14,80 & 15,24 & 15,80 & 16,20 & 18,45 & 16,34 & 16,42 \\
\hline $\mathrm{Na}_{2} \mathrm{O}$ & 2,80 & 2,94 & 3,25 & 2,80 & 3,04 & 3,17 & 3,21 \\
\hline $\mathrm{K}_{2} \mathrm{O}$ & 3,29 & 3,04 & 3,14 & 2,14 & 1,54 & 2,19 & 2,03 \\
\hline $\mathrm{P}_{2} \mathrm{O}_{5}$ & 0,14 & 0,15 & 0,14 & 0,21 & 0,19 & 0,18 & 0,19 \\
\hline Total & 96,58 & 99,03 & 100,82 & 98,73 & 100,45 & 99,53 & 101,01 \\
\hline $\mathrm{Li}$ & - & 15,2 & 15,0 & - & 9,42 & 12,9 & - \\
\hline $\mathrm{Be}$ & - & 1,29 & 1,29 & - & 0,973 & 1,14 & - \\
\hline $\mathrm{Sc}$ & - & 15,1 & 14,4 & - & 24,3 & 21,0 & 21,0 \\
\hline V & 57 & 112 & 104 & 236 & 219 & 174 & 171 \\
\hline $\mathrm{Cr}$ & 6 & 7,04 & 8,84 & 45 & 20,2 & 13,8 & 21,4 \\
\hline Co & - & 13,1 & 11,8 & - & 25,1 & 19,3 & - \\
\hline $\mathrm{Ni}$ & 7 & 4,13 & 3,48 & 26 & 12,2 & 6,83 & 9,0 \\
\hline $\mathrm{Cu}$ & & 53,8 & 45,0 & & 114 & 40,0 & 107 \\
\hline $\mathrm{Zn}$ & 42 & 53,5 & 53,6 & 77 & 71,9 & 69,6 & - \\
\hline $\mathrm{Ga}$ & & 11,5 & 12,7 & & 7,54 & 11,4 & - \\
\hline $\mathrm{Rb}$ & 79,3 & 79,1 & 83,3 & 40,5 & 38,9 & 58,6 & - \\
\hline $\mathrm{Sr}$ & 348 & 383 & 398 & 447 & 553 & 493 & 474 \\
\hline $\mathrm{Y}$ & 26,7 & 28,2 & 28,4 & 26,3 & 23,5 & 26,7 & - \\
\hline $\mathrm{Zr}$ & & 181 & 218 & & 117 & 166 & 113 \\
\hline $\mathrm{Nb}$ & 8,4 & 8,60 & 9,10 & 5,8 & 5,10 & 6,84 & - \\
\hline Cs & 2,19 & 1,91 & 2,03 & 1,08 & 0,895 & 1,37 & - \\
\hline $\mathrm{Ba}$ & 1256 & 1158 & 1225 & 831 & 735 & 975 & 957 \\
\hline $\mathrm{La}$ & 26,0 & 26,4 & 27,3 & 19,8 & 17,7 & 22,0 & - \\
\hline $\mathrm{Ce}$ & 48,5 & 51,7 & 54,5 & 37,3 & 36,1 & 44,4 & - \\
\hline $\operatorname{Pr}$ & 5,8 & 6,69 & 6,96 & 4,7 & 4,81 & 5,77 & - \\
\hline $\mathrm{Nd}$ & 22,8 & 26,7 & 27,5 & 20,0 & 20,5 & 23,6 & - \\
\hline $\mathrm{Sm}$ & 4,9 & 5,45 & 5,55 & 5,1 & 4,47 & 4,99 & - \\
\hline $\mathrm{Eu}$ & 1,04 & 1,23 & 1,31 & 1,33 & 1,30 & 1,31 & - \\
\hline $\mathrm{Gd}$ & 4,36 & 5,15 & 5,22 & 4,68 & 4,39 & 4,84 & - \\
\hline $\mathrm{Tb}$ & 0,7 & 0,809 & 0,830 & 0,8 & 0,689 & 0,758 & - \\
\hline Dy & 4,47 & 4,55 & 4,62 & 4,65 & 3,90 & 4,30 & - \\
\hline Но & 0,90 & 0,933 & 0,954 & 0,95 & 0,794 & 0,887 & - \\
\hline $\mathrm{Er}$ & 2,63 & 2,69 & 2,74 & 2,75 & 2,24 & 2,52 & - \\
\hline $\mathrm{Yb}$ & 2,71 & 2,73 & 2,84 & 2,41 & 2,21 & 2,56 & - \\
\hline $\mathrm{Lu}$ & 0,43 & 0,436 & 0,458 & 0,39 & 0,354 & 0,410 & - \\
\hline Hf & 5,3 & 5,26 & 6,05 & 3,5 & 3,24 & 4,47 & - \\
\hline $\mathrm{Ta}$ & 0,50 & 0,547 & 0,573 & 0,32 & 0,293 & 0,399 & - \\
\hline $\mathrm{Pb}$ & 7,29 & 7,91 & 7,42 & 4,88 & 4,52 & 5,99 & - \\
\hline Th & 6,7 & 7,88 & 8,32 & 3,4 & 3,45 & 5,20 & - \\
\hline $\mathrm{U}$ & 2,69 & 3,64 & 4,03 & 1,32 & 1,75 & 2,60 & - \\
\hline
\end{tabular}

*: Tomadas de Kempter (1997), Tabla 2, p. 82 
más recientes, sugieren esta hipótesis como plausible.

\section{Secuencia piroclástica del cráter Activo}

En la periferia sur del cráter Activo aflora una secuencia de tefras de caída que forman restos de un anillo de tobas que documentan la historia volcánica posterior a la erupción subpliniana Río Blanco, o sea, de los últimos 3700 años. Los aproximadamente $30 \mathrm{~m}$ de tefras corresponden con eventos que han variado desde netamente freáticos con eyección de bloques líticos y sedimentos intralagunares, hasta freatomagmáticos y estrombolianos. El cráter Activo parece ser un cráter de subsidencia, que ha permitido que bloques anulares periféricos hayan descendido a través de fallas, hacia el interior, dando un aspecto de terrazas. Kempter (1997) se preguntaba el porqué a pesar de que las curvas isopacas de la erupción Río Blanco parecían centrar el punto de origen en este cráter, las pómez no aparecen en su periferia inmediata. Cuatro son las posibilidades: 1) la columna piroclástica no permitió la depositación en la parte proximal, como un efecto de sombrilla, 2) la capa de pómez ha sido eliminada por las subsecuentes erupciones del volcán, 3) la capa de pómez esté sepultada por los depósitos del anillo de cenizas y subsidió a lo largo de las fracturas concéntricas al cráter, de modo que está oculta, y solo aparece cerca del cráter von Seebach. 4) o una combinación de estas posibilidades.

En las áreas medias y distales, la ceniza que sobreyace a la Tefra Río Blanco es fina y de poco espesor, lo que indica que no ha sucedido ninguna erupción de importancia, excepto los flujos de escoria del sector norte y la actividad histórica conocida, que se estudia en el siguiente capítulo.

\section{ACTIVIDAD ERUPTIVA HISTÓRICA}

La actividad histórica del Rincón de la Vieja se remonta a la Colonia y se ha caracterizado por periódicas erupciones freáticas y freatomagmáticas, y en menor grado estrombolianas (con bombas escoriáceas, en corteza de pan y cenizas juveniles andesíticas con $\mathrm{SiO}_{2}=57-58 \%$; Boudon et al., 1996, 1997a), concentradas en el cráter principal, con emanaciones de vapor de agua, gases sulfurosos y fumarolas intracratéricas (actividad exhalativa). La figura 8 muestra la distribución temporal de las erupciones y sus características.

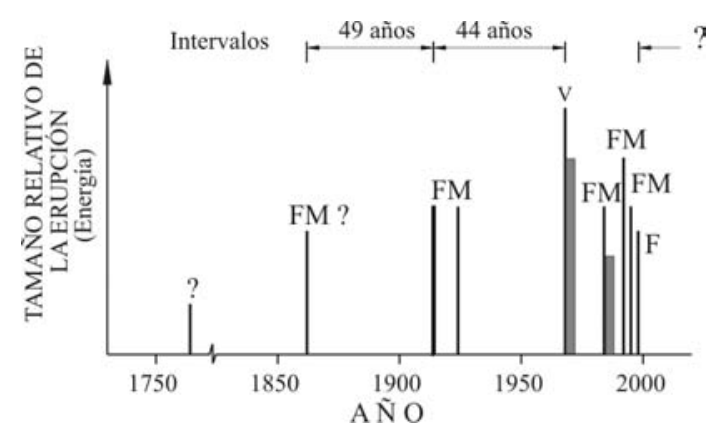

Fig. 8: Distribución temporal de las erupciones del Rincón de la Vieja y sus características (F: freática; FM: freatomagmática; V: vulcaniana).

\section{Erupciones hasta la primera mitad del siglo XX}

Se dice que el volcán Rincón de la Vieja era el "faro natural" de los navegantes en el siglo décimonono, pero bien puede haber sido confundido con un volcán en Nicaragua. En 1765 se da una referencia dudosa sobre una erupción en los Archivos del Museo Naval de España (Boudon et al., 1996). En el año de 1854, Scherzer y Wagner observaron el volcán arrojando humo y reportaron el relato de un hombre de larga data viviendo en las faldas, quien decía que el volcán de vez en cuando arrojaba cenizas incandescentes, pero no hay fechas exactas. En 1860 informaron de actividades esporádicas y en agosto de 1863 se registró una erupción corta (unos tres días) de vapor y de ceniza (Frantzius, 1861; von Seebach, 1865; Pittier, 1912; Sapper, 1925; Trejos, 1959). El 14 de junio de 1912 ocurrieron erupciones similares descritas por Tristán (1921), como una espesa nube negra de humo que se levantó sobre el volcán. Cubrió con abundante 
ceniza la periferia y durante varios días los ríos se tornaron de una coloración blanca lechosa. Entre abril y junio de 1922 ocurrieron fuertes emisiones de vapor y columnas de cenizas, con una actividad similar a la anterior, de tipo estromboliana, con gran cantidad de piroclastos y cráteres de impacto. Entre 1922 y 1955 solo fueron descritas emisiones de vapor y una fuerte actividad fumarólica, en particular en 1940 (Mooser et al., 1958; Boudon et al., 1996). El 29 de junio de 1963 se reportó una emisión constante de nubes de vapor desde el cráter activo, con anhídrido sulfuroso que producía molestias en la garganta y los ojos.

\section{Erupción de 1966-70}

Un período de actividad del Rincón de la Vieja se inició en setiembre de 1966. Las erupciones de ceniza empezaron en octubre y el 6 de noviembre la gente de Liberia divisó penachos de ceniza. Los vecinos del volcán manifestaron que "hacía unos días el volcán había hecho una erupción de grandes proporciones“ (La Nación, 8 de noviembre de 1966). Durante noviembre y diciembre, las erupciones continuaron y la descarga de gases se incrementó notoriamente, afectando los tejados, los alambrados, pastos, sembradíos, la salud de los habitantes y las aguas de los ríos Colorado y Blanco. A finales de noviembre se reportaron al menos dos erupciones diarias y desde principios de diciembre, erupciones intermitentes, separadas por pocos minutos. Las columnas de cenizas y de vapores se alzaban varias centenas de metros sobre el cráter. El área al SSW, hasta unos 10-12 km de distancia del cráter (la hoy llamada "Zona de la Muerte") no se recuperó después de esta erupción. Desde el 19 de diciembre se reportaron retumbos fuertes, incluso escuchados en Liberia, con columnas negras y densas de unos $5 \mathrm{~km}$ de altura, y empezaron a aparecer gran cantidad de peces muertos en los ríos Colorado y Blanco, extendiéndose la mortandad a toda la cuenca oriental del Tempisque (reportes periodísticos de noviembre y diciembre en La Nación, principalmente). Krushensky \& Spencer (1967) hicieron una inspección del área afectada cerca de la cima el 28 de diciembre y reportaron que las cenizas eruptadas eran principalmente accesorias, con $6 \%$ de azufre elemental, 50 ppm de $\mathrm{SO}_{4}$ y $100 \mathrm{ppm}$ de $\mathrm{Cl}$, lo cual confirma la acidez de los productos.

Las primeras dos semanas de enero de 1967, el volcán estuvo relativamente quieto, con solo pequeñas y aisladas erupciones. Por esto, el día 17 de enero de 1967 se organizó una excursión de periodistas y diputados, que se vio interrumpida por la mayor explosión vista hasta ese momento (com. verbal, Leví Vega, 1995), de características freatomagmáticas, que llegó a alcanzar al menos $7 \mathrm{~km}$ de altura sobre el cráter (Fig. 9a), emplazando oleadas y flujos piroclásticos que rellenaron algunas depresiones en la periferia del cráter Activo (Hantke, 1971; Boudon et al, 1997a, b). Varias columnas sucesivas de cenizas, con alturas de centenas de metros fueron reportadas ese día, con formas "de hongo atómico" ( $\mathrm{La}$ Nación, 19 de enero de 1967). Pocos días después se encontró cerca del cráter una capa de ceniza con aproximadamente $100 \mathrm{~cm}$ de espesor que cubrió la vegetación, y se dispersó hasta 20 $\mathrm{km}$ donde se depositaron $0,5 \mathrm{~cm}$ de cenizas finas. Alrededor del cráter, habían bombas y bloques. Las poblaciones de Dos Ríos de Upala y Mayorga fueron evacuadas.

Las erupciones continuaron sin muchos cambios durante enero y febrero. El 15 de febrero se reportaron erupciones cada 30-45 minutos y una grande, con una pluma de cenizas de $2 \mathrm{~km}$ de altura sobre el cráter, a las 2 p.m. (La República, 16 de febrero de 1967). Varios eventos sísmicos leves se reportaron a mediados de febrero, el 23 de febrero se reportaron 28 erupciones en un lapso de 30 minutos y 100 personas más fueron evacuadas de la falda suroeste del volcán (La República, 23 y 24 de febrero de 1967). Una actividad similar, pero en decrecimiento, continuó hasta mediados de 1967 (entrevistas personales y Boza \& Mendoza, 1982). La actividad se reanudó en marzoabril y setiembre-octubre de 1969, cuando se originaron erupciones de lodo con vapor, gas y 


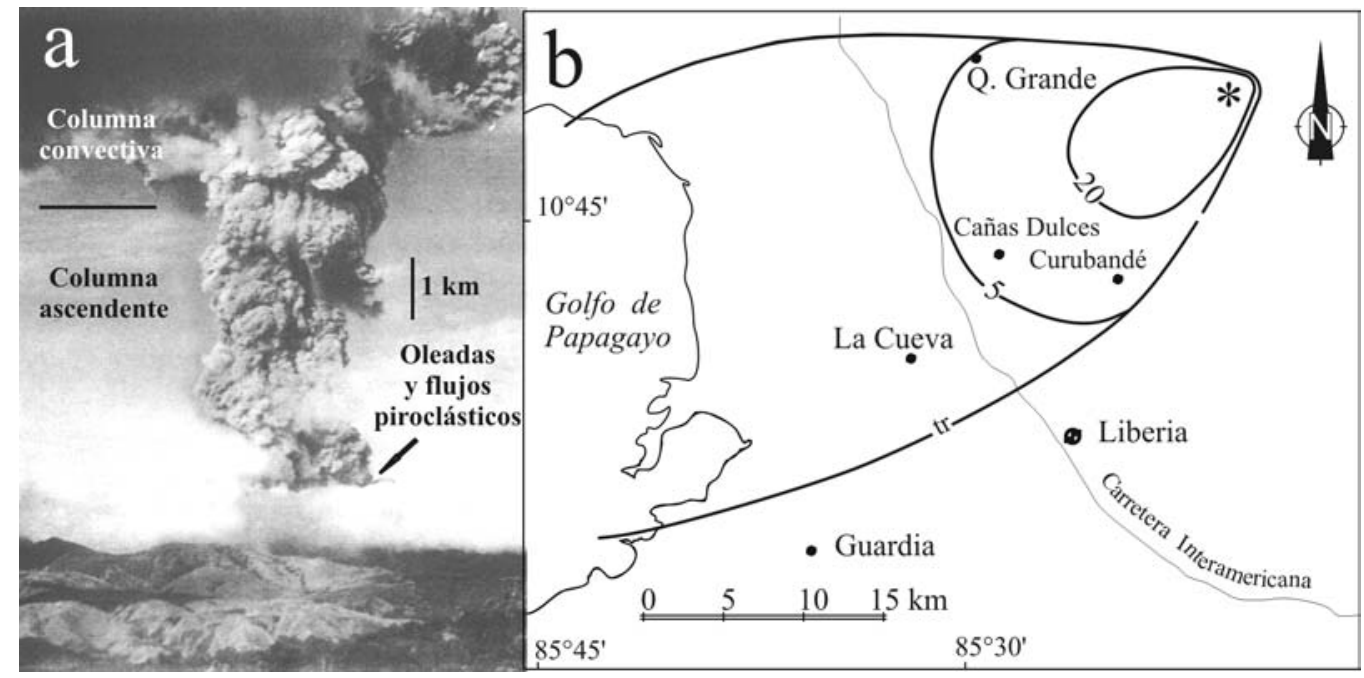

Fig. 9: a) Erupción vulcaniana del 17 de enero de 1967 (15:20, hora local), vista desde Curubandé (Foto cortesía de Óscar Li). b) Curvas isopacas (en mm, tr = trazas) de las cenizas eruptadas durante el período 1966-70.

ceniza, que eran dispersadas hacia el norte. Para julio y agosto de 1970, se informó de nuevas erupciones de ceniza (Mooser et al., 1958; Salguero, 1976; Boza, 1978). Una reconstrucción de la distribución de cenizas, que alcanzaron el Golfo de Papagayo (Fig. 9b), muestra que los productos del ciclo eruptivo 1966-70 cubrieron un área con forma elíptica con el eje en dirección WSW. La mayor parte de las cenizas han sido erosionadas. Inmediatamente al oeste del cráter Activo la secuencia tiene un espesor de 7,5 m; a una distancia de $300 \mathrm{~m}$ del cráter, se preservan solo $40 \mathrm{~cm}$ y a un kilómetro tan solo $15 \mathrm{~cm}$ (Boudon et al., 1996, Fig. 4). Estos depósitos consisten de una alternancia estratificada de piroclastos de caída y de oleadas piroclásticas. Cerca del cráter se pueden distinguir entre 150 y 200 diferentes capas. Desde abajo hacia arriba aumenta la cantidad de fragmentos juveniles vidriosos y de color negro, en detrimento de los fragmentos fuertemente hidrotermalizados. En esta secuencia, sobreyaciendo a una delgada capa de caída, hay un depósito que es el más grueso y, que documenta un evento de flujo piroclástico, el cual se infiere que se formó durante la gran erupción del 17 de enero de 1967.

\section{Erupciones de los años 1980}

En febrero 6 y 21 de 1983 se registraron erupciones fréaticas que afectaron un área pequeña $2 \mathrm{~km}$ al sureste del cráter Activo. Se escucharon retumbos y se observaron erupciones freatomagmáticas que elevaron bloques, lapilli y cenizas hasta una altura de 1,5 km. El 7 y 8 de febrero se observaron avalanchas de barro en el río Pénjamo y la fauna desapareció del río (Barquero \& Segura, 1983; Thorpe et al., 1985). Una actividad freatomagmática más extensa ocurrió en marzo de 1984. Cubrió un área de $4 \mathrm{~km}^{2}$ al sur y sureste del cráter y se generaron corrientes de lodo de 10 a $15 \mathrm{~km}$ de largo que bajaron por los drenajes al norte del volcán (Thorpe et al., 1985). De nuevas erupciones, se informó entre setiembre de 1985 y abril de 1986, que lanzaron piroclastos a $500 \mathrm{~m}$ del cráter Activo y cubrieron $0,25 \mathrm{~km}^{2}$. En diciembre de 1986 hubo una explosión freática de 6 minutos de duración, con la expulsión de bloques de un diámetro $\leq 50 \mathrm{~cm}$, hasta $500 \mathrm{~m}$ del cráter. El $1^{\circ}$ de abril de 1987 hubo otra erupción freática precedida por un sismo, y lahares en los ríos Azufroso y Pénjamo (Boudon et al., 1996). 


\section{Erupción de 1991-92}

Entre mayo de 1991 y setiembre de 1992 se registraron explosiones. La primera de ellas, pequeña, fue el 2 de mayo a las 8:11 a.m., la principal el 8 de mayo a las 10:17 a.m., con una columna de cenizas y vapor que alcanzó $5 \mathrm{~km}$ de altura. Depositó cenizas y bombas alrededor del cráter Activo y originó lahares hacia el norte (ríos Pénjamo, Azul y Azufroso). Del 8 al 11 de mayo hubo un detrimento progresivo de la frecuencia de las explosiones, manteniéndose éstas hasta setiembre de 1992 (Boudon et al., 1996; 1997a).

Los productos de la erupción 1991-92 cubren un área más pequeña y no están tan bien expuestos como los de 1966-70. En el borde occidental del cráter Activo alcanzan un espesor de solo $40 \mathrm{~cm}$ (Boudon et al., 1996). Se distinguen 5 capas: en la base una capa de piroclastos de caída rica en fragmentos hidrotermalizados, sobreyacida por un depósito de flujo de detritos, que devastó parte del bosque al lado sur del cráter. Está compuesto por cenizas, lapilli y fragmentos de lava alterada hidrotermalmente y de fragmentos de una lava fresca, negra y vidriosa. Encima siguen capitas de piroclastos de caída, depositados entre mayo de 1991 y setiembre de 1992.

Durante la erupción del 8 de mayo de 1991 las cenizas cubrieron un área de $200 \mathrm{~km}^{2}$ y llegaron en dirección NW hasta una distancia de $14 \mathrm{~km}$ del cráter (Fernández et al., 1991).

El mecanismo de la erupción del 8 de mayo de 1991 fue por la interacción entre un cuerpo magmático somero, el lago cratérico y el sistema hidrotermal activo (Boudon et al., 1996), probablemente por la oscilación del magma dentro del conducto la cual que se calentó el acuífero superficial. Al interactuar el agua con los gases calientes se produjo la explosión freatomagmática.

Dicha explosión generó corrientes de barro hacia la vertiente norte (región de Upala). Por la fuerza de la erupción, el agua fue empujada hacia arriba y se derramó por el flanco norte, junto con el sedimento que fue expulsado. En su recorrido por la ladera del volcán, arrastró materiales que aumentaron el volumen de la masa. Esto se sustenta por una gran cantidad de cárcavas observadas en ese flanco (no estaban antes de la erupción del 8 de mayo), que expusieron coladas de lava antiguas. El nivel de los lahares en el puente del Río Azul superó los $8 \mathrm{~m}$ de altura. Su velocidad de descenso se estima en $50 \mathrm{~km} / \mathrm{h}$. En el Río Pénjamo, cerca del puente en el camino hacia la región de Buenos Aires, el lahar alcanzó $20 \mathrm{~m}$ de altura, rebalsando el cauce aproximadamente $75 \mathrm{~m}$ a ambos lados. A resultas, los puentes sobre los ríos Azul y Pénjamo fueron destruidos (Fig. 10). El tirante máximo medido de los lahares fue de $15 \mathrm{~m}$, y avanzaron $\sim 11 \mathrm{~km}$ desde su nacimiento en el volcán. En la base del macizo, entre la quebrada Azufrosa y el río Pénjamo, quedó una zona con cerca de $1 \mathrm{~km}$ de ancho arrasada por la avalancha. Árboles truncados indican que la velocidad y el volumen de la avalancha fueron muy grandes al momento de abandonar la pendiente más empinada ( $\mathrm{Pa}-$ niagua et al., 1996).

La actividad posterior a la erupción del 8 de mayo se restringe a temblores menores, emisión de pequeños penachos de ceniza (el 10 y 19 de diciembre de 1991), salidas de gases y posibles lahares (el 13 de enero de 1992), puesto que se detectaron tibias y sulfurosas las aguas río Azul (Paniagua et al., 1996).

\section{Erupción de noviembre de 1995}

En noviembre de 1995 hubo erupciones fuertes de gases, bombas y bloques, y oleadas rasantes de cenizas y vapor, con la subsecuente

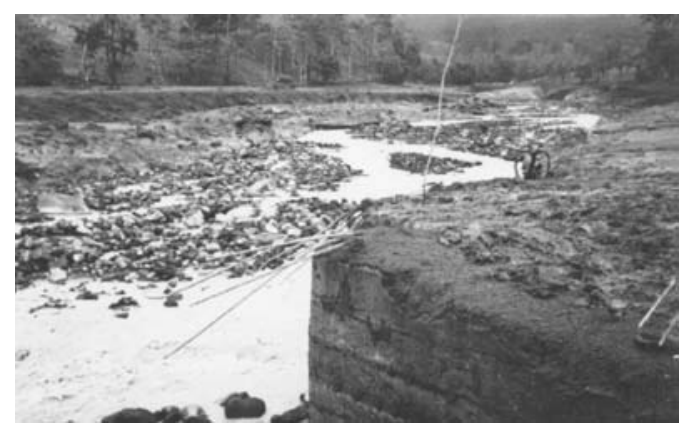

Fig. 10: Lahares en el río Pénjamo, con el puente arrasado, el 8 de mayo de 1991 (Foto de archivos del ICE). 
generación de lahares en los ríos Azul y Pénjamo, y quebrada Azufrada.

En diciembre de 1993, marzo de 1994, diciembre de 1994 y setiembre de 1995, se detectaron picos de emisión de gas radón en el flanco meridional del volcán según datos obtenidos por un grupo geoquímico conjunto franco-costarricense (BRGM de Francia y el ICE). La actividad fréatica observada en abril de 1994 y menormente en mayo de 1995 puede haber estado asociada con estos picos de desgasificación de un cuerpo magmático somero (Soto et al., 2003). Reportes del OVSICORI consignaron un incremento en el número de sismos volcánicos registrados desde junio hasta setiembre de 1995, con un pico en julio. No hay registros en octubre, pero desde el 1 de noviembre, la cantidad de sismos de baja frecuencia se incrementó de 4 hasta 18 el día 5 . Sismos de alta frecuencia aparecieron entre los días 4 y 6.

El 6 de noviembre de 1995 a las 15:04 inició una erupción y a las 19:44 se dio otro evento eruptivo. Una secuencia rítmica de explosiones se dio a lo largo de los días 7 (8 erupciones) y 8 (25 erupciones: datos obtenidos de los registros sismológicos de OVSICORI). Según observaciones aéreas en la mañana del día 8, así como tomas televisivas de Canal 7, y una fotografía aparecida en La Nación, las explosiones eran de características freatomagmáticas, con eyección de vapor y rocas con diferentes ángulos balísticos y oleadas rasantes, producto de la interacción entre el sistema de agua de la laguna, el agua subterránea y un cuerpo magmático en enfriamiento a poca profundidad. Las primeras explosiones del día 6 probablemente fueron de carácter fréatico. Las más grandes se registraron el día 7 a las 13:34, cuya columna de cenizas y vapor se estima se elevó unos 4 km encima del cráter, y el día 8 a las 9:54. Las columnas piroclásticas observadas durante un sobrevuelo del día 8 se elevaban entre unos 500 y 1000 m sobre el cráter, y el vapor de agua y gases fueron eyectados hasta unos 2 ó 3 km sobre aquél (Boudon et al., 1997b).

El día 9, la actividad cambió a un comportamiento netamente fumarólico de alta intensidad, levantando columnas de vapor de unos 200 a $300 \mathrm{~m}$ antes de ser barridos por el viento.
Asimismo, numerosos eventos de explosiones de vapor se suscitaron durante ese día, levantaron una columna de vapor de $\sim 1,5 \mathrm{~km}$ sobre el cráter.

El área total afectada fue de $\sim 350 \mathrm{~km}^{2}$. En un radio $\leq 1 \mathrm{~km}$ del cráter, hubo bombardeo por bloques y ceniza, hacia la vertiente norte, que da a las nacientes de los ríos Pénjamo y Azul. En la cúspide se encontraron espesores de cenizas que variaban desde $\operatorname{los} 2 \mathrm{~mm}$ a $2,5 \mathrm{~cm}$. Caída de bloques, hasta distancias de $600 \mathrm{~m}$ del borde del cráter fueron reportadas, con cráteres de impacto $\leq 2 \mathrm{~m}$ de diámetro por $0,5 \mathrm{~m}$ de profundidad. Un análisis químico de una bomba corteza de pan con matriz oscura vítrea lustrosa (Cuadro 6), concuerda con los productos emitidos recientemente del cráter Activo (cf. Carr et al., 1986).

En un área que se extiende al este-suroeste, se dispersaron cenizas finas y gases barridos por los vientos. Las cenizas finas recorrieron distancias máximas de 70 km en dirección WNW. Simulaciones realizadas por Campos (1997) para esta erupción, no obstante, sugieren que concentraciones de ceniza en el aire, de $10-100 \mu \mathrm{g} \mathrm{m}^{-3}$ son posibles a alturas de 6-11 km, unos $2000 \mathrm{~km}$ al oeste, tres días después de la erupción.

El flanco norte (distancia $\leq 11 \mathrm{~km}$ ) fue afectado por corrientes lodosas y lahares calientes que inhabilitaron el puente sobre el río Pénjamo y socavaron profundamente el vado sobre la quebrada Azufrada, que comunica hacia el asentamiento Agroindustrial Sur producto de la acumulación de material piroclástico en las vertientes altas, así como la eyección de lodo y la mezcla de ambos con precipitaciones pluviales durante los días 7 y 8 . En el río Pénjamo, donde pasa de un río encajonado (unos $10 \mathrm{~m}$ de profundidad) a un río abierto, cerca de la cota de $460 \mathrm{~m}$, los tirantes máximos de los lahares fueron de 8-9 m, sólo rebalsando el cauce en puntos localizados. Desde el día 9, las crecidas arrastraban material en suspensión, así como rocas de menor diámetro a las de los dos días anteriores. Los poblados, que al momento de las erupciones se consideraron amenazados y fueron parcialmente incomunicados, fueron Agroindustrial Sur (Asentamiento del IDA), Asentamiento La Flor, Buenos Aires, Gavilán y La Vega. 
Los lahares del 7 de noviembre eran más ricos en agua y más fríos que los del 8 de noviembre. Si bien se considera que las erupciones de noviembre de 1995 fueron más vigorosas que las de mayo de 1991, la generación de lahares de 1991 fue mucho mayor en volumen y extensión. Las velocidades de los lahares de noviembre de 1995 fue calculada utilizando datos de las avalanchas en el Río Pénjamo (Fernández et al., 1995 y Paniagua et al., 1996), entre 23,6 y 94,3 $\mathrm{km} \mathrm{h}^{-1}$ (promedio de $50,1 \mathrm{~km} \mathrm{~h}^{-1}$; Soto et al., 2003). El tiempo que tomaron para viajar los 11 $\mathrm{km}$ desde el momento de la erupción hasta el arribo al puente, tuvo un rango de 7 a 28 minutos, con un promedio de 16 minutos.

Los depósitos de los lahares han sido descritos con detalle por Soto et al. (2003), puesto que días después de los eventos de noviembre de 1995, se pudieron acceder varios afloramientos (Figs. 11, 12) en la vecindad del puente sobre el río Pénjamo. Los depósitos, en su mayoría, son rápidamente erosionados y normalmente presentan secuencias incompletas. Los afloramientos actuales presentan lahares que subyacen o sobreyacen a los flujos piroclásticos descritos supra. En la figura 11, los horizontes A corresponden
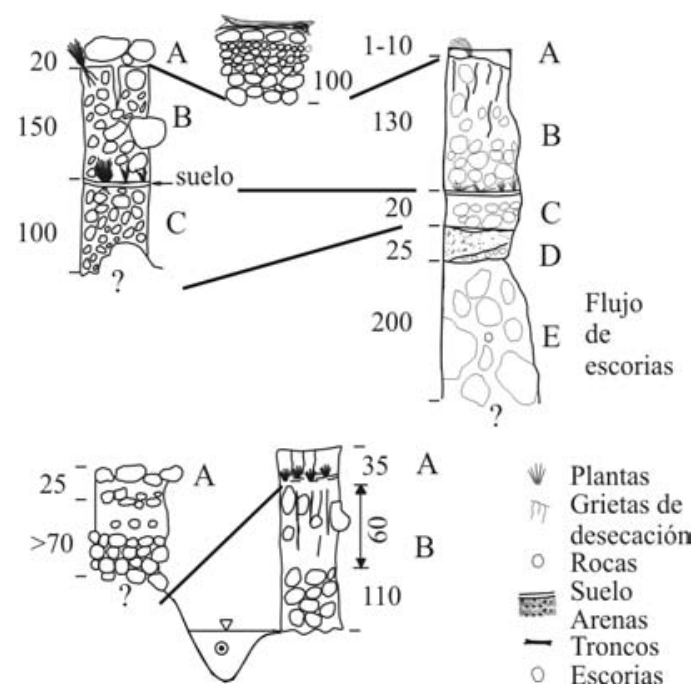

Fig. 11: Columnas y correlación de los lahares (espesores en $\mathrm{cm}$ ) producidos en el Rincón de la Vieja en noviembre de 1995 (A), mayo de 1991 (B), sin fecha conocida (C y D), y el flujo de escorias de 1520 a.P., en el río Pénjamo.

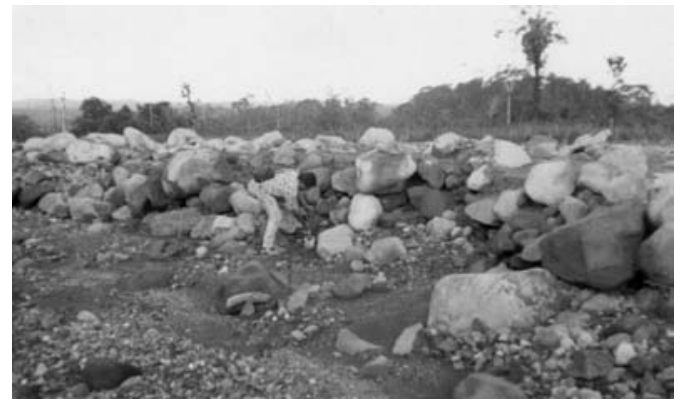

Fig. 12: Depósitos de los lahares de noviembre de 1995 en el río Pénjamo.

con los lahares de 1995, los horizontes B con los de 1991, los C y D son de fecha desconocida y el horizonte $\mathrm{E}$ son los flujos piroclásticos de 1520 a.P. Como se deduce de sus características granulométricas y texturales, corresponden con toda una gama desde flujos de lodo y arenas, hasta flujos hiperconcentrados de detritos.

La capa A (de 1995) está constituida por bloques subredondeados, con diámetros entre 5 $100 \mathrm{~cm}$, en contacto puntual con islas de arenas y barros volcánicos grises de unos $50 \mathrm{~cm}$ de espesor, con grietas de desecación. Los fragmentos son polilitológicos: Lavas vítreas, porfiríticas, negras, grises, rojizas, vesiculares; brechas hidrotermalizadas; terrones de brechas muy meteorizadas y fragmentos ricos en azufre. Grandes troncos de árboles y los bloques mayores se ubican hacia la superficie del depósito, estando los espacios entre bloques superficiales ocupados por gravas, arenas y limos, debajo de los cuales se presentan gravas de hasta $20 \mathrm{~cm}$ de diámetro y menos en contacto puntual con poca matriz. Hacia los bancos laterales, la parte inferior del nivel muestra arenas con guijarros angulosos a subredondeados $(<5 \mathrm{~cm})$, con una ligera laminación paralela y horizontal, flotando, como un lente que se adelgaza rápidamente. Las grietas no lo afectan.

El nivel intermedio B (de 1991) está dividido (contacto no neto) en dos subniveles. El de arriba posee una mayor concentración de matriz tamaño arena media a fina, con fragmentos de lavas andesíticas en contacto puntual a flotante. Posee fracturas verticales abiertas con paredes oxidadas (grietas de desecación). Hacia la base 
se presentan clastos $<60 \mathrm{~cm}$ y un nivel rico en troncos y bases de árboles in situ, encima de un nivel de suelo negro de $10-15 \mathrm{~cm}$ de espesor.

El nivel C está constituido por cantos subredondeados a subangulosos $(<20 \mathrm{~cm})$ de lavas andesíticas negras, en contacto puntual con poca matriz intraclastos. Poseen laminación paralela e inclinada y una tosca gradación inversa. El nivel D es un nivel de arenas limosas, café, homogéneas, inconsolidadas con guijarros flotando $(<1 \mathrm{~cm})$, hacia la base con cantos $(\sim 5 \mathrm{~cm})$ y arenas localmente. Lateralmente, grada a material más grueso. Este nivel se comporta casi como un suelo.

\section{Erupción de febrero de 1998}

El lunes 16 de febrero de 1998 el Rincón de la Vieja hizo otra erupción. Según los guardaparques, desde hacía un mes se veían burbujas grandes en la laguna y una acentuada actividad fumarólica. El 15 en la mañana, la laguna cratérica mostraba un nivel bajo. Los reportes sismológicos dicen que una actividad sísmica anómala se inició ese día en la tarde, mientras que los visuales hablan de una erupción el día 16 a las 5:14 a.m. Esta generó un lahar tibio que se distribuyó por los ríos Pénjamo, Azul y Azufrosa. El tirante máximo observado alcanzó apenas $50 \mathrm{~cm}$ sobre los puentes de estos ríos. Durante el resto del día, solo hubo erupciones frecuentes de vapor con muy poca ceniza blancuzca (23 reportadas, pero como estuvo nublado, podrían haber habido cerca de una centena), cuyos penachos se elevaron unos $300 \mathrm{~m}$ sobre el cráter. La última erupción con ceniza ocurrió el martes 17 a las 10:20 a.m., con una altura estimada de la columna en $~ 1000$ $\mathrm{m}$, luego se mantenía una intensa actividad fumarólica, que impedía observar el interior del cráter. No hubo daños materiales ni personales, solo la muerte de peces.

Las áreas de impacto por los productos emitidos durante las erupciones fueron:

1. Cerca del cráter, hasta un radio máximo de $300 \mathrm{~m}$ por bombardeo de bloques. En el borde sur del cráter, el lodo expulsado formó un depósito gris claro, de $6 \mathrm{~cm}$ de espesor.

2. Los ríos Colorado y Blanco, en la vertiente sur, no fueron afectados, pues el material caído en sus cabeceras fue exiguo. La generación de crecientes lodosas calientes se concentró hacia el lado norte hasta unos $5 \mathrm{~km}$ del cráter.

3. Un área pequeña, con un eje dirigido hacia el W-WSW, hacia donde las cenizas finas fueron barridas por los vientos. La ceniza se detectó hasta $3 \mathrm{~km}$ y formó lapilli acrecional submilimétrico.

Las erupciones fueron fréaticas. Con base en el material emitido, el tamaño de la erupción de 1998 es al menos dos órdenes inferior a la de 1995. Aparte de que la erupción fue pequeña, la poca cantidad de agua y lodo presentes en el cráter, y el hecho de ser una estación bastante seca, incidieron para que los lahares fueran de poca monta.

\section{ACTIVIDAD FUTURA}

Las erupciones individuales han perdurado desde pocas horas hasta una o dos semanas. Algunas de ellas, empero, se agrupan en lapsos de 5 a 7 años. La historia de las pasadas erupciones del Rincón de La Vieja indica que tiene una alta probabilidad de entrar en erupción en un futuro cercano (años). Un análisis de su registro histórico (150 años de registro más o menos confiable: Cuadro 7) muestra que se han producido al menos 10 erupciones significativas desde 1863 (si excluimos la dudosa de 1765).

Antes de 1863 no hay erupciones bien establecidas con su fecha, pero parece lógico asumir algunas pequeñas erupciones, al menos desde los reportes de 1854. Con esto, se podrían agrupar 6 períodos eruptivos: 1854?-63, 1912, 1922, 1966-70, 1983-87, 1991-98. Debemos tener en cuenta de que la completitud del registro no es la óptima, en particular antes de los años sesentas del siglo XX. Estadísticamente es aventurado, pero podemos hipotetizar que hay lapsos de 40 a 50 años de quietud entre las erupciones históricas 
Cuadro 7

Lapsos intereruptivos históricos del volcán Rincón de la Vieja.

\begin{tabular}{cc}
\hline Año de la erupción & $\begin{array}{c}\text { Período desde la } \\
\text { anterior erupción (años) }\end{array}$ \\
\hline $1765 ?$ & $\vdots ?$ \\
1863 & $98 ?$ \\
1912 & 49 \\
1922 & 10 \\
$1966-70$ & 44 \\
$1983-87$ & 13 \\
$1991-98$ & 4 \\
$2038 ? ?$ & 40 \\
\hline
\end{tabular}

mayores. El período eruptivo que se extiende desde 1991 hasta 1998, parece anómalo. Es posible que la erupción de 1991 haya sido disparada por el Terremoto de Limón del 22 de abril, 15 días antes de la primera erupción del Rincón. Además, parece ser que los períodos mencionados se iniciaban con erupciones freáticas, seguidas casi inmediatamente por erupciones freatomagmáticas $\mathrm{y}$, al final del período, erupciones netamente freáticas. Es posible que pequeños cuerpos de magma suban hasta una cámara somera y sean evacuados en un período eruptivo, hasta que suba uno nuevo. Se podría pronósticar una erupción importante de aquí al año 2038 (Cuadro 7), eventualmente interrumpido por pequeños eventos, en particular si ocurriera un sismo regional de gran magnitud. A modo de comparación, existe una estimación de erupción del Rincón de la Vieja para el año 2021, según Trombley (2003).

\section{CONCLUSIONES}

Las erupciones del Rincón de la Vieja durante los últimos 4000 años han sido netamente explosivas. Los estudios tefroestratigráficos documentan dos eventos explosivos de grandes dimensiones.

El primero, la Tefra Río Blanco, hace 3770 \pm 130 años, involucró un magma diferenciado de una cámara pasiva por un largo período. Al haber ocurrido una inyección de magma andesítico, se disparó la erupción, que se dio en seis fases: 1) apertura del cráter; 2) pulsante, con un aumento de la energía hacia el final; 3) abre y cierra con eventos freatomagmáticos, con una sola gran explosión en el medio, en donde la contribución de magma andesítico se incrementa y hay una fase de apertura del conducto; 4) clímax de la erupción, con pulsos que permiten la incorporación de agua subterránea y la generación de explosiones freatomagmáticas; 5) una explosión de menor cuantía, con eventos freatomagmáticos al inicio y final, y 6) una explosión, en donde la componente freato-magmática es importante.

En el sector norte del volcán afloran los productos del segundo gran evento. Son flujos piroclásticos restringidos a los valles de los ríos Azul y Pénjamo hasta unos $10 \mathrm{~km}$ al norte del cráter Activo. Su edad calibrada es 1520 +80110 años a.P.

Una comparación entre los flujos piroclásticos del lado norte y la Tefra Río Blanco, hace hipotetizar un escenario eruptivo en el que un remanente del magma dacítico fue expulsado de la cámara ante la invasión del magma andesítico hace 1520 años. Eso explica la base rica en pómez de los flujos piroclásticos, similar a la Tefra Río Blanco. Asimismo, la similitud geoquímica de las andesitas de esa erupción y de las erupciones más recientes, sugiere que el magma ha permanecido en una cámara somera durante los últimos 1500 años, con pulsos que generan explosiones.

Las mayores erupciones históricas del Rincón de la Vieja han sido vulcanianas, estrombolianas y freáticas. Históricamente, la mayor erupción ocurrió entre 1966-70, en particular entre diciembre de 1966 y febrero de 1967, cuando bombas, bloques y cenizas destruyeron la vegetación a más de $2 \mathrm{~km}$ del cráter. Erupciones subsiguientes, afectaron áreas más pequeñas, pero todas han generado lahares hacia el lado norte, que varían desde flujos de lodo hasta flujos hiperconcentrados de detritos.

Parecen haber períodos de reposo de 40 años, seguidos por erupciones menores y un nuevo período de reposo de unos 10 años, para retornar a otra erupción freatomagmática importante, o un grupo de ellas en un lapso de 5-7 años. 


\section{AGRADECIMIENTOS}

A Chico Arias por su invaluable asistencia en el campo. El Instituto Costarricense de Electricidad promovió y financió el trabajo de campo y la datación radiométrica referida. Michael J. Carr (Rutgers University) realizó el análisis químico de la bomba de 1995 y Jennifer Wade (Boston University) los de las escorias y pómez. Javier Sihézar, del Parque Nacional Rincón de la Vieja, brindó apoyo logístico durante el trabajo de campo.

\section{REFERENCIAS}

BARQUERO, J. \& SEGURA, J., 1983: La actividad del volcán Rincón de la Vieja. - Bol. de Vulcanología, 13: 510, Heredia.

BOUDON, G., RANÇON, J.-P., KIEFFER, G., SOTO, G.J., TRAINEAU, H. \& ROSSIGNOL, J.-C., 1996: Les éruptions de 1966-70 et 1991-92 du volcan Rincón de la Vieja, Costa Rica: exemple d'activité récurrente d'un système hydromagmatique. - C.R. Acad. Sci. Paris, 322, IIa: 101-108.

BOUDON, G., RANÇON, J.-P., KIEFFER, G., SOTO, G.J., TRAINEAU, H. \& ROSSIGNOL, J.-C., 1997a: Estilo eruptivo actual del volcán Rincón de la Vieja: evidencias de los productos de las erupciones de 1966-70 y 1991-92. - Rothschildia, 2,2: 10-13.

BOUDON, G., SOTO G.J., ALVARADO G.E., VILLEMANT, B. \& ROSSIGNOL, J.-C., 1997b: The November 1995 hydromagmatic eruption of Rincón de la Vieja (Costa Rica): Recurrent activity of an active hydrothermal system. - [res.] IAVCEI General Assembly Volcanic Activity and the Environment, Puerto Vallarta, México, enero 19-24 de 1997, Abstracts: 147.

BOZA, M.A., 1978: Los Parques Nacionales de Costa Rica. - 224 págs. INCAFO, S.A., Madrid.

BOZA, M.A. \& MENDOZA, R., 1982: The National Parks of Costa Rica. - 310 págs. INCAFO, S.A., Madrid.

CAMPOS, E., 1997: Simulación de la dispersión de ceniza durante las erupciones de noviembre de 1995 del volcán Rincón de la Vieja. - Top. Meteor. Oceanog. 4(1): 5-13.
CARR, M. J., CRAIG, A. \& BRUCE, G., 1986: Nuevos análisis de lavas y bombas del Rincón de La Vieja, Costa Rica. - Bol. de Vulcanología, 16: 23-30, Heredia.

CAS, R.A.F. \& WRIGHT, J.V., 1988: Volcanic successions. Modern and ancient. - 528 págs. Unwin Hyman Ltd., Londres.

CHIESA,S., ALVARADO, G.E., PECCHIO, M., CORELLA, M. \& ZANCHI, A., 1994: Contribution to petrological and stratigraphical understanding of the Cordillera de Guanacaste lava flows, Costa Rica. - Rev. Geol. Amér. Central, 17: 19-43.

FERNÁNDEZ, E., BRENES, J. \& BARBOZA, V., 1991: La actividad eruptiva del volcán Rincón de La Vieja, durante los días 6, 7 y 8 de mayo de 1991. - Bol. de Vulcanología, UNA, 22: 11-17.

FERNÁNDEZ, E., BRENES, J., SEGURA, J. \& BARBOZA, V., 1995: Actividad eruptiva del volcán Rincón de La Vieja, de los días 6-13 de noviembre 1995. - OVSICORI-UNA,. Heredia, Costa Rica, 10 págs. [Informe inédito].

FRANTZIUS, A. VON, 1861: Beiträge zur Kenntniss der Vulkane Costarica's. - Petermann's Mittheilungen, Gotha, Heft IX: 329-338.

HANTKE, G., 1971: Rincón de la Vieja. Annual report of volcanic activity. - Bul. Volc. Erupt. Bull. Volcanol. 34,2: 7-8.

KEMPTER, K., 1997: Geologic evolution of the Rincón de la Vieja Volcanic Complex, NW Costa Rica. - 192 págs. Univ. of Texas at Austin [Tesis PhD].

KEMPTER, K., BENNER, S.G. \& WILLIAMS, S.N., 1996: Rincón de la Vieja volcano, Guanacaste province, Costa Rica: geology of the southwestern flank and hazard implications. - J. Volcanol. Geother. Res. 71: 109-127.

KRUSHENSKY, R.D. \& SPENCER, F.D., 1967: Effects of recent eruptions of the volcano Rincón de la Vieja, Costa Rica. - Costa Rica Investigations. US Geol. Surv., 6 págs. [Nota técnica inédita].

MELSON, W. G., 1988: Major explosive eruptions of Costa Rica volcanoes. - Update for Costa Rica Volcanism Workshop, Costa Rica Volcanism, Washington 1418, Nov., 1988, 6 págs. [inédito].

MOOSER, F., MEYER-ABICH, H. \& MCBIRNEY, A., 1958: Catalog of active volcanoes of the world including 
solfatara fields. Central America. - Intern. Volcanol. Ass. IV:133-146.

PANIAGUA, S., SALAZAR, L.G., KUSSMAUL, S., MONGE, A. \& OBANDO, L.G., 1996: Síntesis de la amenaza volcánica y estimación básica del riesgo del volcán Rincón de la Vieja, Cordillera de Guanacaste, Costa Rica. - Escuela Centroamericana de Geología, Universidad de Costa Rica, 64 págs. [Informe interno].

PITTIER, H., 1912: Costa Rica, Beiträge zur Orographie und Hidrographie. - Pettermann's Mittheilungen, Gotha 37(175):1-48.

SALGUERO, M., 1976: Volcanes de Costa Rica. - 48 págs. Ed. Costa Rica.

SAPPER, K., 1925: Los volcanes de la América Central. 144 págs. Max Niemayer, Halle.

SEEBACH, K. VON, 1865: Reise durch Guanacaste (Costa Rica) 1864 und 1865. - Petermann's Mitt. Heft VII:241-249.

SOTO, G.J., ALVARADO, G.E., GOOLD, S. \& CLIMENT, A., 2003: Evaluación del peligro y riesgo volcánico que representa el volcán Rincón de la Vieja para el
Proyecto Geotérmico Las Pailas, Cordillera de Guanacaste, Costa Rica. - Inst. Costarricense de Electricidad, Área de Amenazas y Auscultación Sísmica y Volcánica, 79 págs. [Informe interno].

STUIVER, M. \& REIMER, P.J., BARD, E., BECK, J.W., BURR, G.S., HUGHEN, K.A., KROMER, B., McCORMAC, G., VAN DER PLICHT, J., \& SPURK, M. 1998: IntCal98 radiocarbon age calibration, 24,000-0 BP. - Radiocarbon, 40: 1041-1083.

THORPE, R. BROWN, G., RYMER, H., BARRIT, S. \& RANDAL, M., 1985: Recent Volcano Monitoring in Costa Rica. - Earthq. Inf. Bull. 17(2):44-49.

TREJOS, J.F., 1959: Geografía de Costa Rica. - 347 págs. Imprenta Universal, San José.

TRISTÁN, J.F., 1921: Apuntes sobre el Volcán Rincón de la Vieja. - Rev. de Costa Rica, II,7:193-206.

TROMBLEY, R.B., 2003: Holocene Volcanic Activity in the Caribbean Plate Margins: Forecast and Risk Assessment. Caribbean volcanic activity and forecast report. 15 January 2003. http://www. ig.utexas.edu/CaribPlate/forum/volcanoes/index.htm 